\title{
The Rebound Effect of Information and Communication Technologies Development in the European Union
}

\author{
Piotr Werner
}

Received: 10 June 2014 / Accepted: 14 October 2014 /

Published online: 28 October 2014

C The Author(s) 2014. This article is published with open access at Springerlink.com

\begin{abstract}
Information Society technologies are aimed at raising productivity while reducing time and costs of materials and energy for the economy. Specialists have also observed that Information and Communication Technologies (ICT), which have become significantly cheaper, are in huge demand for individual (household) use. Individual applications of ICT in the European Union (EU) economy are leading to a growth in different human activities. Their impacts on the economies of EU countries are analogous to the well-known take-back (rebound) effect, which increases the efficiency of resource use. The aim of study is to reveal factors and spatial patterns of dissemination of ICT technology in the EU households and comparison of their electrical energy consumption. The study is based on the comparison of partial indices of the information society, an explanation of the energy rebound effect (take-back effect) and statistical analysis of spatial data using shift and share analysis, leading to a redefinition of the explanatory compound components (factor analysis), which in turn are visualized using Geographic Information Systems (GIS) tools.
\end{abstract}

Keywords Rebound effect · Households · Electric energy - Spatial patterns · ICT · EU

\section{Introduction}

Institutions and individuals observing the global information society agree that Information and Communication Technologies (ICT) 'can be a development enabler, if applied and used appropriately' and 'is critical to countries that are moving towards information or knowledge-based societies' (ITU 2009). ITU reports (2012, 2013) confirm a global growth in ICT, especially the number of mobile-cellular and fixed (wired)-broadband subscriptions with a decline in the price of services. The aim of study is to reveal factors and spatial patterns of dissemination of ICT technology in the European Union (EU) households and comparison of their electrical energy

P. Werner $(\bowtie)$

Faculty of Geography and Regional Studies, University of Warsaw, Krakowskie Przedm.30,

00-927 Warsaw, Poland

e-mail: peter@uw.edu.pl 
consumption. Research hypotheses assume that ICT growth in EU countries during the last decade is the main factor in the growth of electric energy consumption and the relation between these phenomena is based on the take-back effect rather than simply a stimulation in the demand for energy services.

The study is based on the comparison of partial indices of the information society, an explanation of the energy rebound effect (take-back effect) and statistical analysis of spatial data using shift and share analysis, leading to a redefinition of the explanatory compound components (factor analysis), which in turn are visualized using GIS tools.

\section{Measuring the Information Society}

The construction of the ICT Development Index (IDI, ITU 2013) encapsulates three dimensions: readiness, use and capability with appropriate sub-indices: access, use and skills. Input data are from the country level. Intensity of usage of ICT measures its uptake (ibid.) involving the composition of three indicators: Internet users per 100 inhabitants, fixed (wired)-broadband subscriptions per 100 inhabitants, and wirelessbroadband subscriptions per 100 inhabitants.

The growing use of ICT in developed and developing countries also has vast social and economic implications, both positive and unexpected (although it is difficult to say that they could be negative). Usually the positive economic impacts are highlighted. Faster communication, ease of use, growth in the range of services and revenues and a rise in individuals' free time allowance are perceived as the advantages.

Information and communication technologies are also perceived as the tool for energy efficiency growth in transport, industry and services (e.g. global navigation systems, management information systems). The main aims of ICT implementation are defined as a rise in productivity, time and costs savings of materials and energy, as well as effectiveness (Bomhof et al. 2009). Such opinions have been partly confirmed for industry and transport, for example by statistics concerning the final consumption of electric energy during the last decade in Europe (Fig.1).

On the other hand, specialists have also observed that new ICT technologies, which have become significantly cheaper, are attracting more and more interest and are in high demand, both in the market as well as in households, for individual use (Golinski 2011). The trend for the wider use of ICT in services and by households is also positively correlated with final consumption of electric energy (Fig.1).

Nowadays billions of new ICT mobile and wired devices are available on the market. They must also be supplied with battery chargers and, alongside traditional devices like refrigerators, air-conditioning, TV sets etc., contribute to a greater demand for electric energy in the households. Of course, they are all compliant with the directives of energy efficiency. The lives of individuals and households are easier and less time is required to meet basic and higher needs.

But it is too simplistic to perceive this phenomenon in terms of the functional relationship between the demand for services and the number of new subscribers using new ICT devices. In both transport and industry, a comparable number of new generation ICT devices (with much higher power consumption) have also been implemented, but the actual final consumption of electric energy has not risen. 


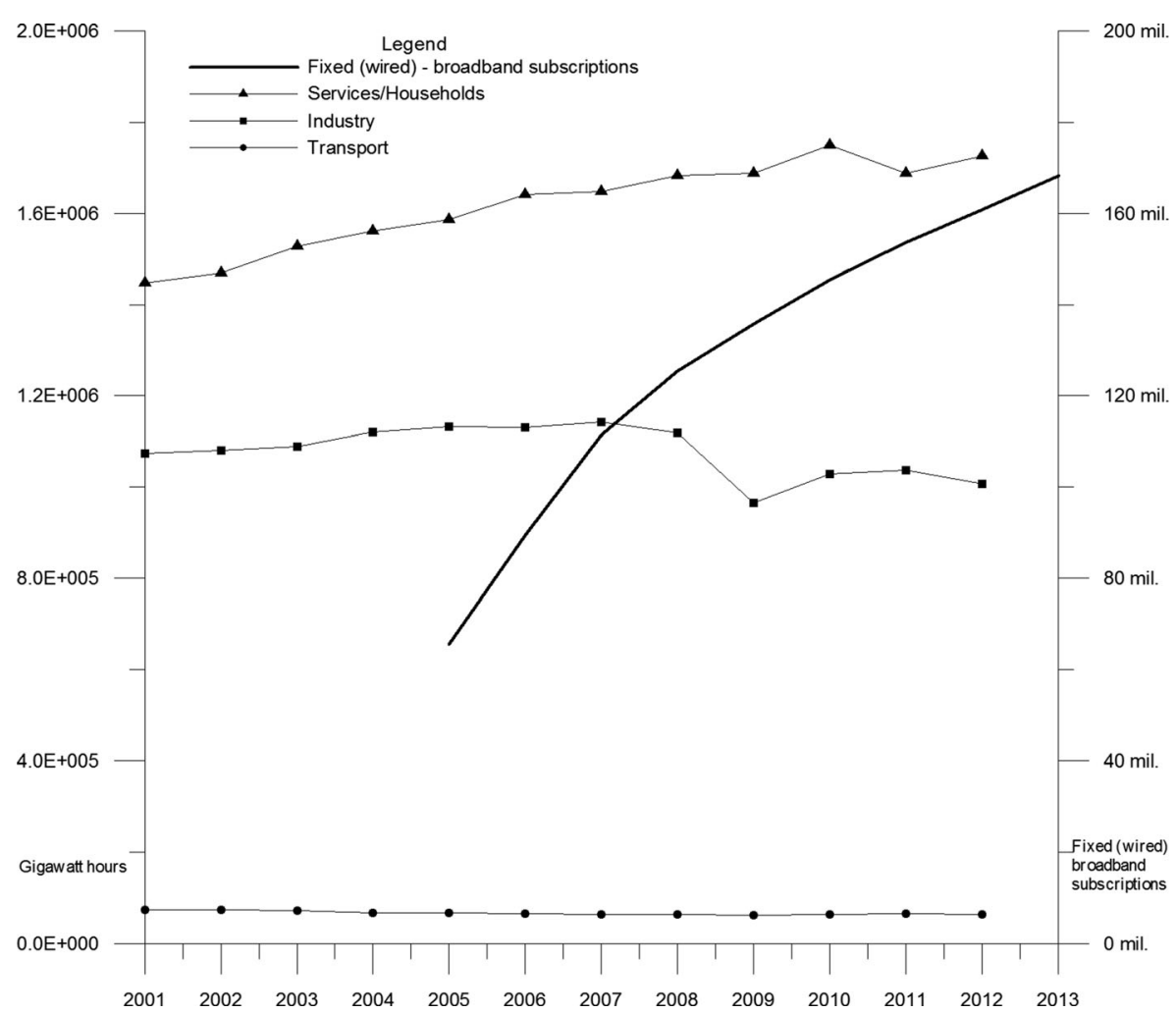

Fig. 1 Consumption of electricity by industry, transport activities and households/services in Europe (EU-28, source: Eurostat data, Eurostat table code: ten00094; Gigawatt hours, 2014); Number of fixed (wired)broadband subscriptions in Europe (source: ITU, 2013)

The situation described was previously identified in the history of the economy and has recently been redefined once again by specialists as the so-called 'rebound effect'.

\section{The Rebound Effect}

The rebound effect refers to the relationship between improvements in technological efficiency which lead to an increase in per capita consumption (http://www.cdist.dk 2014). Nowadays it is defined as the actual growth of the consumption of an energy service as the price decreases (Bomhof et al. 2009).

Historically this phenomenon has only been described for the energy sector, and nowadays is known as the Jevons paradox (so-called take-back effect). 'A rebound effect happens when an energy efficient technology is implemented instead of an old one, and when it creates an opposite effect to what could be expected: the new technology does not reduce the total quantity of energy consumed, but increases it. Being more efficient, it cheapens the energy costs and calls for larger uses' (Missemer 2012:98).

Hilty (2008) treats this phenomenon in the context of ICTs as third-order (tertiary) environmental effect: '[tertiary] environmental effects of the medium- or long-term 
adaptation of behavior (e.g. consumption patterns) and economic structures to the availability of ICT and the services it provides'. Recently there have been many examples of this, such as increasing paper consumption or increasing traffic (ibid.). Bomhof et al. (2009) describes four kinds of effects. Direct rebound effects are related to better energy efficiency, which in turn decreases the prices at the micro level. Second order rebound effects arise from the greater consumption of other products due to savings. Third order rebound effects are related to the balance of all products in the whole economy. Fourth order rebound effects concern changing consumer preferences and the organisation of productions (ibid).

The roots of this phenomenon can be found in the context of ICT with the application of the so-called 'anthropotropic principle' of the evolution of media (Levinson 1998). The evolution of recent media (e.g. mobile ICT devices) is towards more human functions (ibid.).

The potential of ICT application to reduce energy consumption can be confronted with three main ecological benefits, in the form of dematerialization (e.g. the substitution of the obsolete CD-ROM with USB), more efficient production processes (e.g. lower prices for better quality printouts) and altered human behaviour (Bomhof et al. 2009). An example of changing human behaviour is the BYOD (BYOT, BYOP) rule bring (and use elsewhere) your own device (technology, phone). The information and energy resources of the employer are free for employees, who use personally owned devices during work. Often, in turn, the opposite situation takes place i.e. permission to use employer devices or resources at home or on journeys.

On the other hand, strong goal displacement is marked ${ }^{1}$ by the use of information and communication technologies. People's unintentional use of ICT and other media (not in the original manner projected by the inventors) was highlighted by Levinson (1998).

\section{Factors Affecting the Rebound Effect of ICT}

The deployment and dissemination of ICT may rise because of growth in the national economy correlated with a target policy of the national government. Use of ICT is perceived as catalyzing element in economy and leads to rise effectiveness (Baliamoune-Lutz 2003). The economic interests of ICT-specialized commercial firms (as well as at the international level) are another factor stimulating the development and dissemination of ICT. The competence and competitiveness of firms and their workers interact with national policy. Positive effects of ICT growth are related to importance of knowledge flows as a source of economic growth. Maurseth and Frank (2009) pointed also that ICT may stimulate growth in other industries that use ICT in their production processes. The third factor that plays an important role is local authority policy and a lagging knowledge economy at the regional level. ICT improve economic institutions and change the way economic activities are carrying out. ICT are treated in this context as the set of general-purpose technologies, which are related to shift in technological

\footnotetext{
${ }^{1}$ Goal displacement: the process by which the means used to achieve a goal become more important than the goal itself; for example, recently the use of the cellular telephone is also (and often) aimed at self-entertainment rather than telephone calls.
} 
paradigm. They are characterized by widespread use, strong externalities, complementariness, and fast growth (ibid:607)

\section{Research Methodology}

\section{Shift and Share Analysis}

The shift and share method is the analysis of the statistical change of different points of time. The shift-share approach analyses the changes in economic magnitudes between two periods by identifying three components: a national effect, a sectorial effect and a competitive effect (Mayor and López 2008). Ranges of the applications involve, inter alia: analysis of economic growth, employment changes, business demographics, regional inequality, international trade (Woźniak and Mogiła 2013), and also crime rates (Blair and Mabry 1980) and urban population (Batty 2006).

The shift and share technique is well known and widely used, and is the obvious methods for quantification of geographical changes (Dunn 1960). However, it has barely been considered in the spatial context of dependences (Mayor and López 2008).

The idea at the foundation of the method is the decomposition of mathematical identities (SS) into three components: the national share effect (NS), industry mix (IM, also called a structural, proportional or industrial effect) and the regional effect (also differential or competitive, RS; Woźniak and Mogiła 2013).

$$
S S=N S+I M+R S
$$

where: SS Total Shift-Share, NS National Share, IM Industry Mix, RS Regional Shift.

Net variation (TS) in the observed total variables is described as the value that is not predicted by national share:

$$
T S=I M+R S
$$

National share (NS) concerns the portion of change in the observed phenomena in a region which would have occurred there if the total quantity in this region grew at the same rate as at the national level. NS describes the expected regional change compared to the dynamics of the whole economy (e.g. region vs. country, country vs continent). This measure holds the observed share of the variable in the region constant (Mitchell et al. 2007).

Industry mix (IM) concerns the overall national sectorial growth rate of the observed phenomena (taken into account). It is the measure of the portion of regional change related to sectorial changes. This is structural change, i.e. deviation of the variable's growth rate. A negative IM means a slowdown in technology. A region which is growing fast nationally will have a positive IM, whereas a region with a sector which is growing slowly (or declining) nationally will have a negative IM (ibid).

Regional shift (RS) is a residual component, the difference in the observed and expected changes of the phenomena. It is also called the competitive effect. RS is perhaps the most important component. It highlights a local area's economic strengths 
(Oguz and Knight 2011). Regional shares represent the variation of growth rates between regions (Mitchell et al. 2007).

The traditional interpretation of shift and share analysis is based on the comparison of total shares (TS) with observed IM and RS components. If the TS are positive, the regions are growing faster and, on the contrary, a negative TS implies the slower growth of the regions. The following situations are to be considered (analogous to ibid):

- NS-IM-RS synergy: TS $>0, \mathrm{IM}>0, \mathrm{RS}>0$, then the country (region) grows faster than the European average with industry composition and local factors providing advantages.

- NS-IM synergy: TS $>0, \mathrm{IM}>0, \mathrm{RS}<0,|\mathrm{IM}|>\mid \mathrm{RS}$, then the country (region) grows faster than the European average due to a favourable composition offsetting unfavourable local factors.

- NS-RS synergy: TS $>0, \mathrm{IM}<0, \mathrm{RS}>0,|\mathrm{RS}|>|\mathrm{IM}|$, then the country (region) grows faster than the European average with local factors offsetting the unfavourable industry mix.

- RS-IM discordance: TS $<0, \mathrm{IM}>0, \mathrm{RS}<0,|\mathrm{RS}|>|\mathrm{IM}|$, then the country (region) grows slower than the European average due to disadvantageous local factors, but offset by the favourable industry mix.

\section{Input Data, Transformations and Visualizations}

Verification of the assumed hypothesis required the selection of appropriate spatial variables, which were the following: share of fixed (wired)-broadband subscriptions in households and share of households with Internet access in 27 EU countries (NUTS 0, with NUTS 1 and NUTS 2) ${ }^{2}$, representing intensity of use of ICT (2006-2012, source of data: Eurostat ${ }^{3}$ ). The base variable was the total number of households during the period 2006-2012, assuming that they represent expected growth of demand for ICT. The second approach of shift and share analysis concerned the final consumption of electricity in households, but more complete data were only available for the NUTS 0 level (countries) for the observed period.

\section{Factor Analysis (FA)}

The results of the evaluated shift and share analyses were (9) variables which were then transformed into compound factors (using factor analysis). The number of studied variables was reduced (in order to show the prevalence of each of the components mentioned above) into a smaller number of new variables, which can in turn be reinterpreted to reveal their spatial differentiation. For this purpose, Factor Analysis (FA) is used primarily for data reduction and/or structure detection. The objective of data reduction is to remove redundant (highly correlated) variables from the data file, perhaps replacing the entire

\footnotetext{
2 The NUTS classification (Nomenclature of territorial units for statistics) is a hierarchical system for dividing up the economic territory of the EU for the purpose of the collection, development and harmonisation of EU regional statistics; NUTS 0: countries, NUTS 1: major socio-economic regions, NUTS 2: basic regions for the application of regional policies.

${ }^{3}$ European Statistical Office
} 
data file with a smaller number of uncorrelated variables. Structure detection is used to examine the underlying (or latent) relationships between variables. The aim is to reveal the complex components with a very clearly defined influence on the rebound effect of the information society. The interpretation allows these components to be named. The first step was principal component analysis (PCA). For PCA the Statistica software package was used. The PCA method produced a solution using principal component extraction (not rotated). The components with eigenvalues were saved. The extraction communalities are estimates of the variance in each variable accounted for by the components. The high values of communalities indicate that the extracted components represent the variables well. The next steps of FA concerned only the chosen subset of initial components of PCA with a satisfactory level of representation and variance of the initial variables.

\section{Results and Interpretation}

The numerical findings of the shift and share analyses are presented in Fig. 2. All the presented data concern countries. Some detailed spatial differentiations of shift and share components related to the information society are also presented on a map as a compound view (NUTS 0, 1 and 2 together), with the most detailed layer (NUTS 2) on top. The lack of data on the top layer (NUTS 2) is supplemented by the NUTS 1 and in turn the NUTS 0 layers.

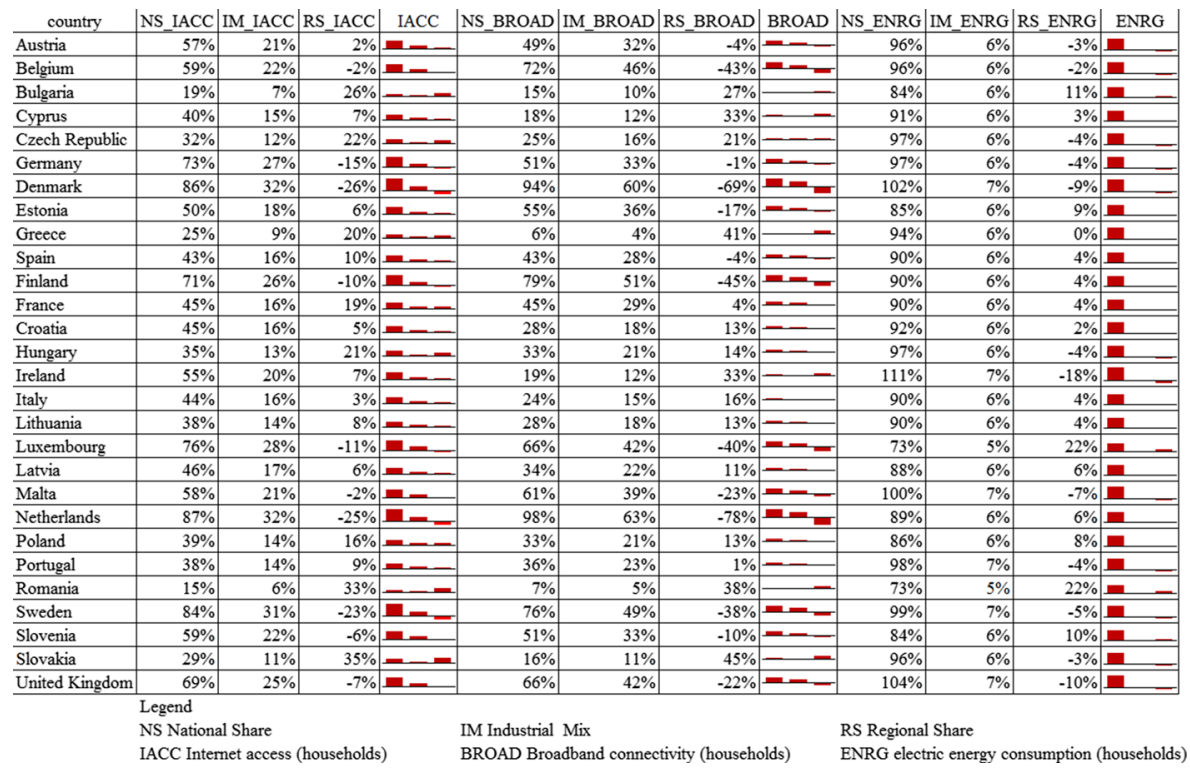

Fig. 2 Decomposition of growth (2006-2012) in share of Internet access (IACC) and broadband share of Internet connections (BROAD); measured by share of households (\%) in EU countries and growth in final consumption of electric energy (ENRG, Gigawatt hours) in households into shift and share analysis components: national share (NS), industry mix share (IM) and regional share (RS). See description in text (source of input data: Eurostat, 2014) 
According to Eurostat (2014), the total number of households in the (28) EU countries grew during 2006-2012 by $9.22 \%$, reaching 214.3 million. During the same period, the share of the total level of Internet access (measured by percentage of households connected to the Internet) grew from 51 to $79 \%$ (variable: iacc). However, the share of broadband Internet access by households (variable: broad) grew simultaneously from 31 to $76 \%$ (all households having at least one member in the age group 16-74 years, Eurostat table code: tin00073, 2014).

During the period from 2006 to 2012, the total consumption of electric energy in transport, industry and services/households declined by $1 \%$ (from 2,836, 104 to 2,798,168 Gigawatt hours) but grew in the services/households sector by $5 \%$ (from 1,640,379 to 1,726,270 Gigawatt hours, variable: enrg, Eurostat table code: ten00094, 2014).

The shift and share decomposition of the growth in total share of Internet access and broadband connectivity in households in Europe proved the spatial differentiation of the observed components (Fig.2). The decomposition of growth in use of electric energy (2006-2012) into shift and share components was presented simultaneously.

The share of broadband connections in households grew synergistically in Europe at all levels: national, sectorial and regional (NS-IM-RS synergy and NS-IM synergy). However, in the case of Denmark, the Netherlands and several regions in central England (UK), a discordance of regional (RS) and sectorial (IM) components is observed (Fig.3). EU regions (NUTS 1 and 2) are usually characterized by the same tendencies as at the country level (NUTS 0), with the exception of certain parts of France, Germany, Austria, Spain, southern part of the Republic of Ireland, Southern Portugal, North-Eastern Poland and Northern Ireland. Detailed analysis proved the occurrence of smaller shares (unfavourable local factors) in the regional component (RS). Local factors offsetting the unfavourable industry mix (NS-RS synergy) were not noted anywhere in the EU.

Three of the studied variables - share of Internet access, broadband share of Internet connections measured by share of households (\%) in EU countries, and growth in final consumption of electric energy (Gigawatt hours) - were decomposed into 9 variables, denoting national shares, industry mix and regional share components for each country. These were the input data for the FA.

For the initial solution there were as many components as variables, and in the correlations analysis the sum of the eigenvalues equals the number of components. According to the assumption that eigenvalues greater than 0.7 are extracted, the first three principal components formed the extracted solution (Table 1). The extracted components explained over $96 \%$ of the variability of the original nine variables, so the complexity of the data set was significantly reduced by using these components, with only a $4 \%$ loss of information. The rotation maintained the cumulative percentage of variation explained by the extracted components, with that variation spread more evenly over the components. The notable changes in the individual totals suggest that a rotated component matrix will be more easily interpreted than a non-rotated one (Table 2).

The rotated component matrix helped to determine what the factors represent; these were the correlation coefficients. The first factor was most highly correlated with national shares and industry mix components for Internet access 


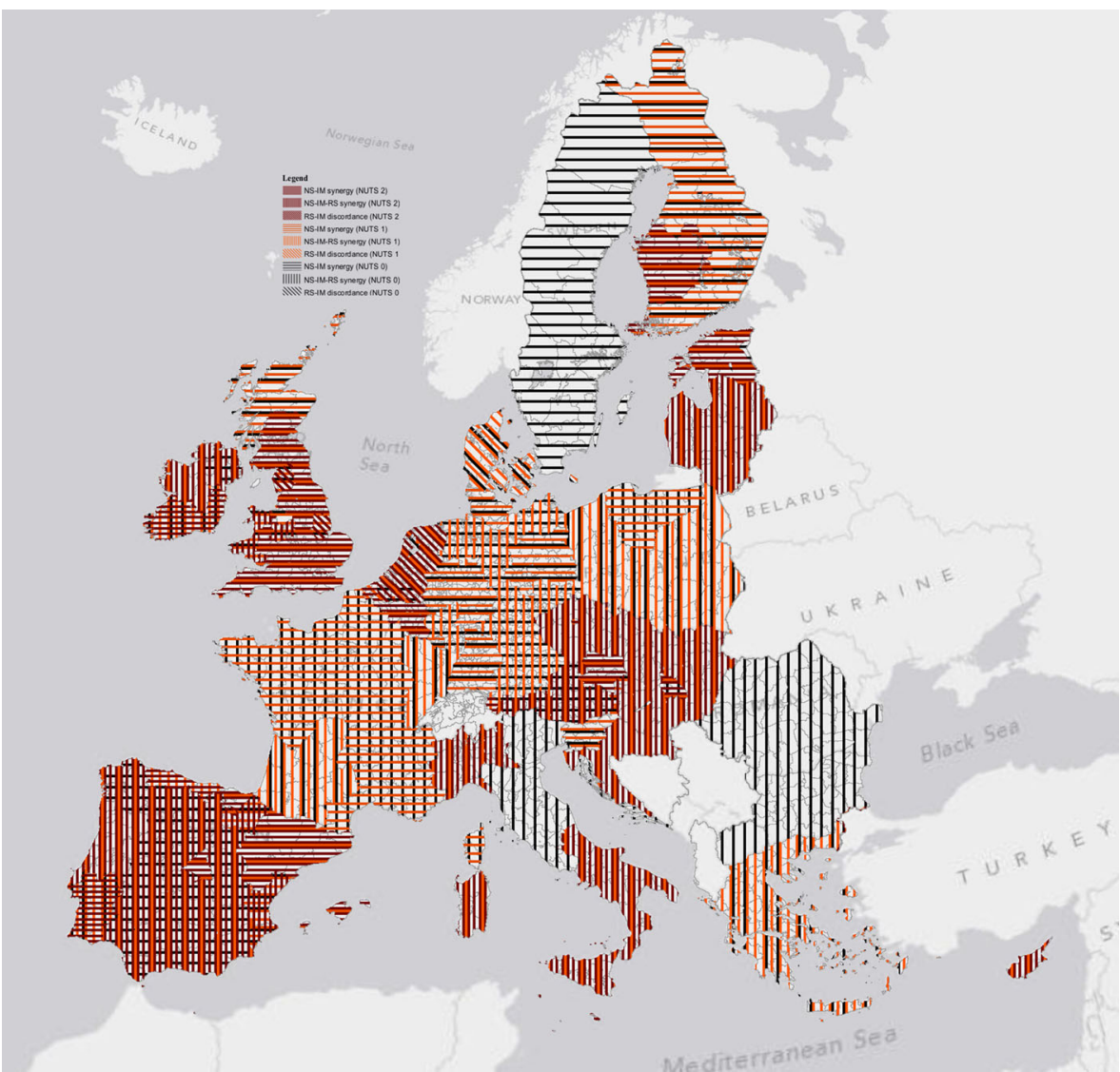

Fig. 3 Synergy and discordance of national share (NS), industry mix (IM) and regional share (RS) components of growth in Internet broadband connection share of households in the EU by NUTS 0,1 and 2 (2006-2012, source of data: Eurostat 2014, see description in text, base map ESRI, De Lorme; ArcGIS)

and broadband connectivity. Simultaneously it was less correlated with the other variables. This factor (1) was defined as the impacts of the ICT sector at the EU level and from the EU ICT industry mix. Newly introduced ICT devices and services at the EU level, also from international enterprises, attract the attention and users (in households) because offer a relatively innovative and easier access to greater volume of resources and advantages of faster data-

Table 1 Rotation Sums of Squared Loadings of PCA, Extraction Method: Principal Component Analysis. StatSoft, Inc. (2011). STATISTICA (data analysis software system), version 10. www.statsoft.com

\begin{tabular}{lllll}
\hline Factors & Eigenvalue & \% Total (variance) & Cumulative (Eigenvalue) & Cumulative (\%) \\
\hline 1 & 5.78 & 64.17 & 5.78 & 64.17 \\
2 & 1.96 & 21.79 & 7.74 & 85.96 \\
3 & 0.93 & 10.38 & 8.67 & 96.35 \\
\hline
\end{tabular}


Table 2 Interpretation of Factor Loadings (Quartimax raw, ten00094last.sta), Extraction: Principal components, (Marked loadings are $>0.7$ ), StatSoft, Inc. (2011). STATISTICA (data analysis software system), version 10., www.statsoft.com

\begin{tabular}{|c|c|c|c|}
\hline Variables/Factors & $\begin{array}{l}\text { Factor }(1) \\
\text { international } \\
\text { ICT impacts }\end{array}$ & $\begin{array}{l}\text { Factor (2) } \\
\text { international } \\
\text { pattern of household } \\
\text { electric energy } \\
\text { consumption impacts }\end{array}$ & $\begin{array}{l}\text { Factor ( } 3 \text { ) } \\
\text { national pattern } \\
\text { of household electric } \\
\text { energy consumption } \\
\text { impacts }\end{array}$ \\
\hline $\begin{array}{l}\text { NS_IACC } \\
\text { National share of internet access } \\
\text { in households }\end{array}$ & 0.96 & 0.09 & -0.14 \\
\hline $\begin{array}{l}\text { IM_IACC } \\
\text { Industry mix share of internet } \\
\text { access in households }\end{array}$ & 0.96 & 0.09 & -0.14 \\
\hline $\begin{array}{l}\text { RS_IACC } \\
\text { Regional share of internet access } \\
\text { in households }\end{array}$ & -0.94 & -0.03 & 0.16 \\
\hline $\begin{array}{l}\text { NS_BROAD } \\
\text { National share of broadband } \\
\text { connectivity in households }\end{array}$ & 0.98 & 0.03 & 0.05 \\
\hline $\begin{array}{l}\text { IM_BROAD } \\
\text { Industry mix of broadband } \\
\text { connectivity in households }\end{array}$ & 0.98 & 0.03 & 0.05 \\
\hline $\begin{array}{l}\text { RS_BROAD } \\
\text { Regional share of broadband } \\
\text { connectivity in households }\end{array}$ & -0.97 & 0.03 & -0.11 \\
\hline $\begin{array}{l}\text { NS_ENRG } \\
\text { National share of final electric energy } \\
\text { consumption in households }\end{array}$ & 0.12 & 0.99 & -0.05 \\
\hline $\begin{array}{l}\text { IM_ENRG } \\
\text { Industry mix of final electric energy } \\
\text { consumption in households }\end{array}$ & 0.12 & 0.99 & -0.05 \\
\hline $\begin{array}{l}\text { RS_ENRG } \\
\text { Regional share of final electric energy } \\
\text { consumption in households }\end{array}$ & -0.23 & -0.10 & 0.96 \\
\hline Expl.Var & 5.66 & 2.00 & 1.01 \\
\hline Prp.Totl & $63 \%$ & $22 \%$ & $11 \%$ \\
\hline
\end{tabular}

transfer speed. In this context the first factor may be abbreviated by the term: international ICT impacts (on Internet use by households). The second factor (2) was correlated with national share and industry mix variables for the level of final consumption of electric energy in households. It was defined as the impact of the EU level and industry mix pattern of electric energy consumption by households. Similarly, during the observed time interval, electrical energy production and distribution technologies have been also developed (and they absorbed also ICT technologies), and in turn, they have shaped the patterns of consumption of electric energy. In this context the second factor may be abbreviated by the term: international pattern of household electric energy 
consumption impacts. The last factor (3) was only very highly correlated with the regional (in the study: country) share of electric energy consumption in households and was strictly defined as the impact of the country (regional) pattern of electric energy consumption by household. These patterns are related to consumption of prevailing, specific sources of energy, and in turn, the ways the secondary i.e. electric energy is used to use. In this context the third factor may be abbreviated by the term: national pattern of household electric energy consumption impacts.

For each EU country and each factor, the factor score was computed by multiplying the case's original variable values by the factor's score coefficients (Table 2). The resulting standardized (average $=0$, standard deviation $=1$ ) three factors (score variables) are representative, and can be used in place of the nine original variables with only a $4 \%$ loss of information. They have also been plotted on maps (Figs. 4, 5, 6).

It should be noticed that high international ICT impacts on the rebound effect took place (during 2006-2012) in Finland, Sweden, Denmark,

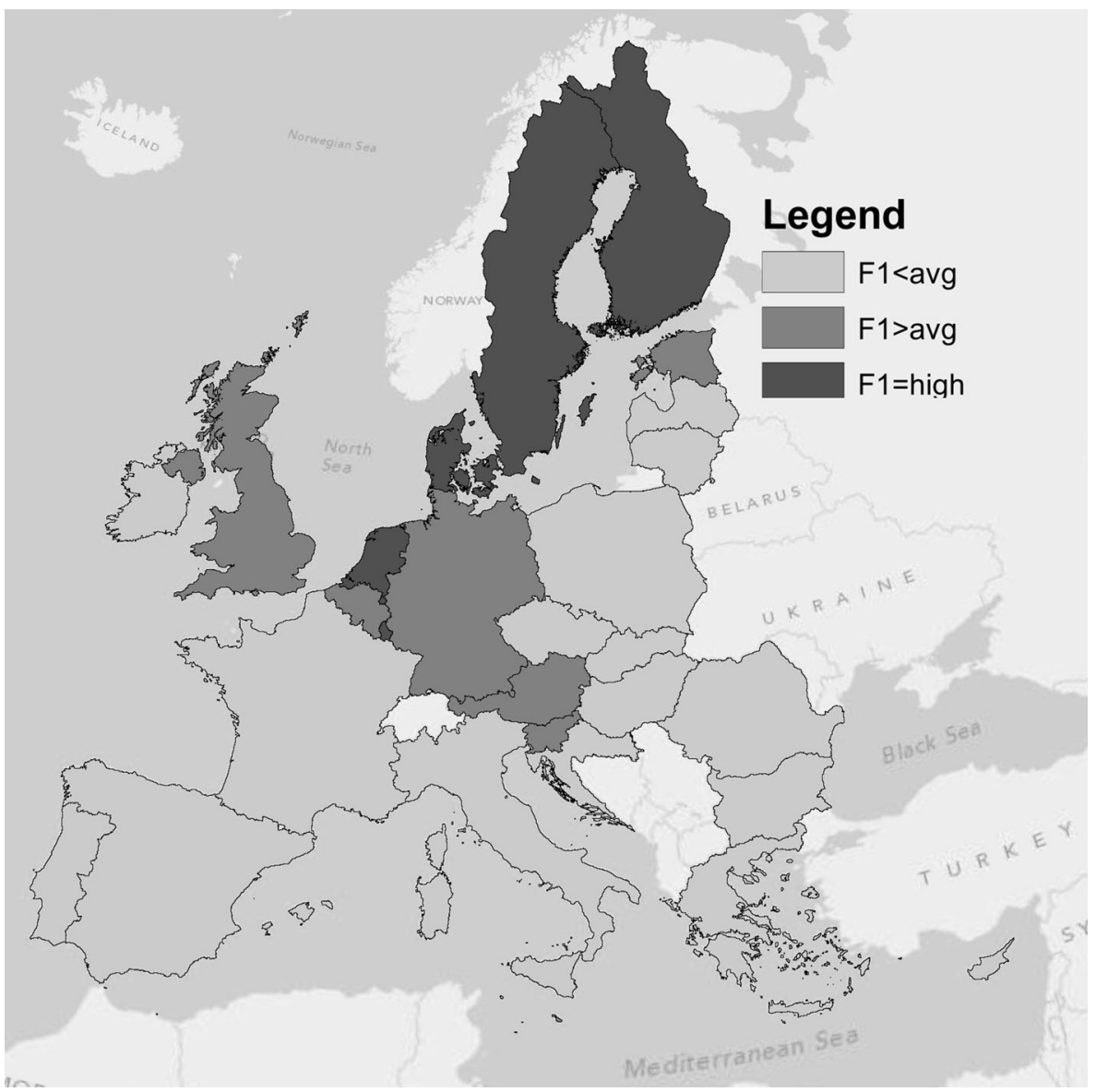

Fig. 4 Factors of the rebound effect in EU countries (2006-2012): international ICT impacts (F1) 


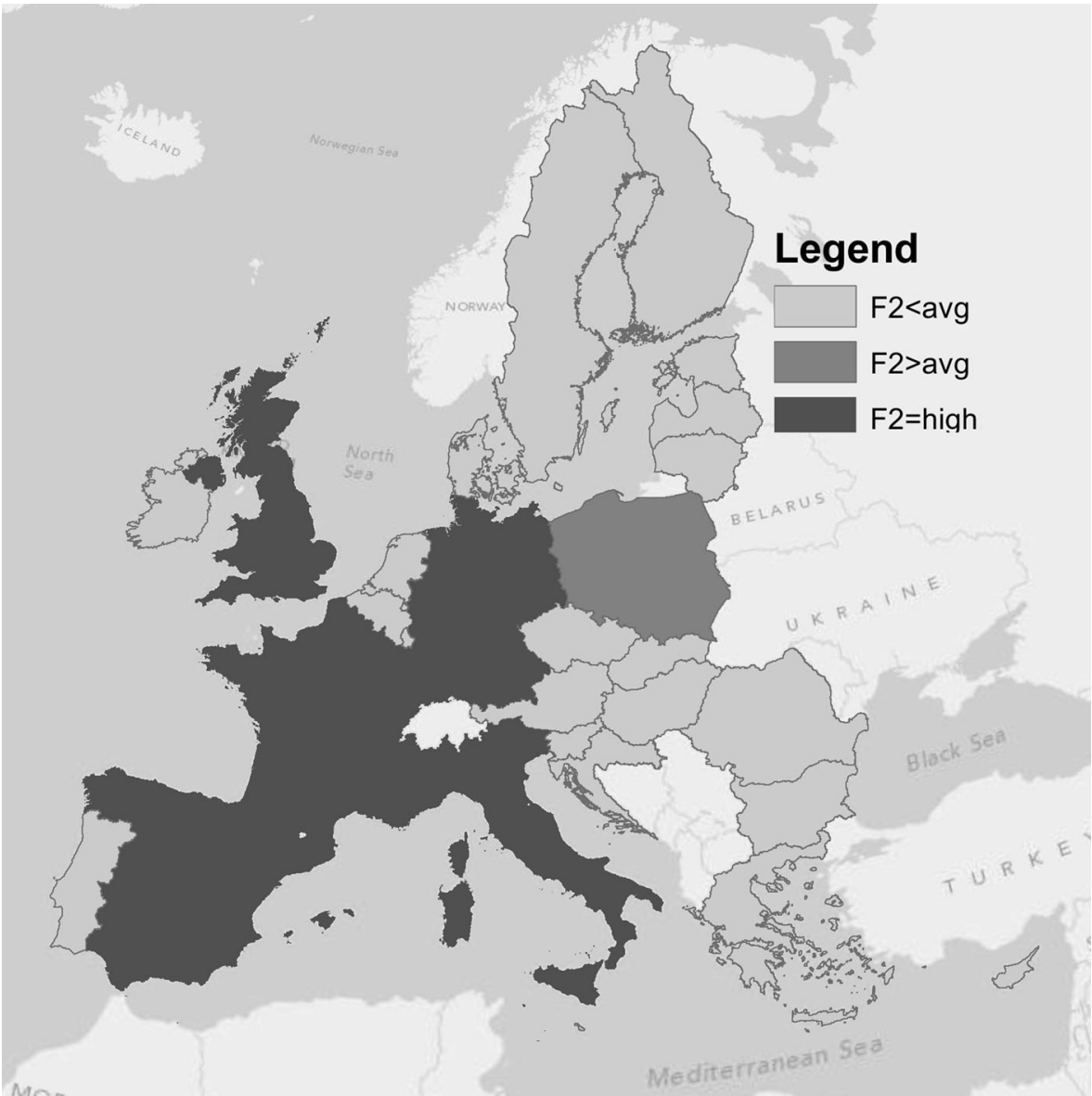

Fig. 5 Factors of the rebound effect in EU countries (2006-2012): international pattern of electric energy consumption impacts (F2)

Netherlands and Luxembourg. These countries formed a compact spatial cluster, surrounded by others, with a relatively low significance of this factor (Fig.4). The second cluster involves countries which also form a compact zone near the borders of those mentioned above. These are the United Kingdom, Belgium, Germany, Austria, Slovenia and Estonia, with values of international impacts of ICT higher than average.

Germany, the United Kingdom, France, Spain and Italy are also characterized by the highest values of impacts on the rebound effect of the international pattern of electric energy consumption (Fig.5). The other countries are characterized by below-average values (with the exception of Poland).

France, Spain and the Netherlands are the three countries with the highest impacts of national patterns of household electric energy consumption (Fig.6). The second group of specific national patterns of household electric energy consumption (above average) comprises Finland, Estonia, Denmark, Poland, Romania, Bulgaria, Italy and Belgium. 


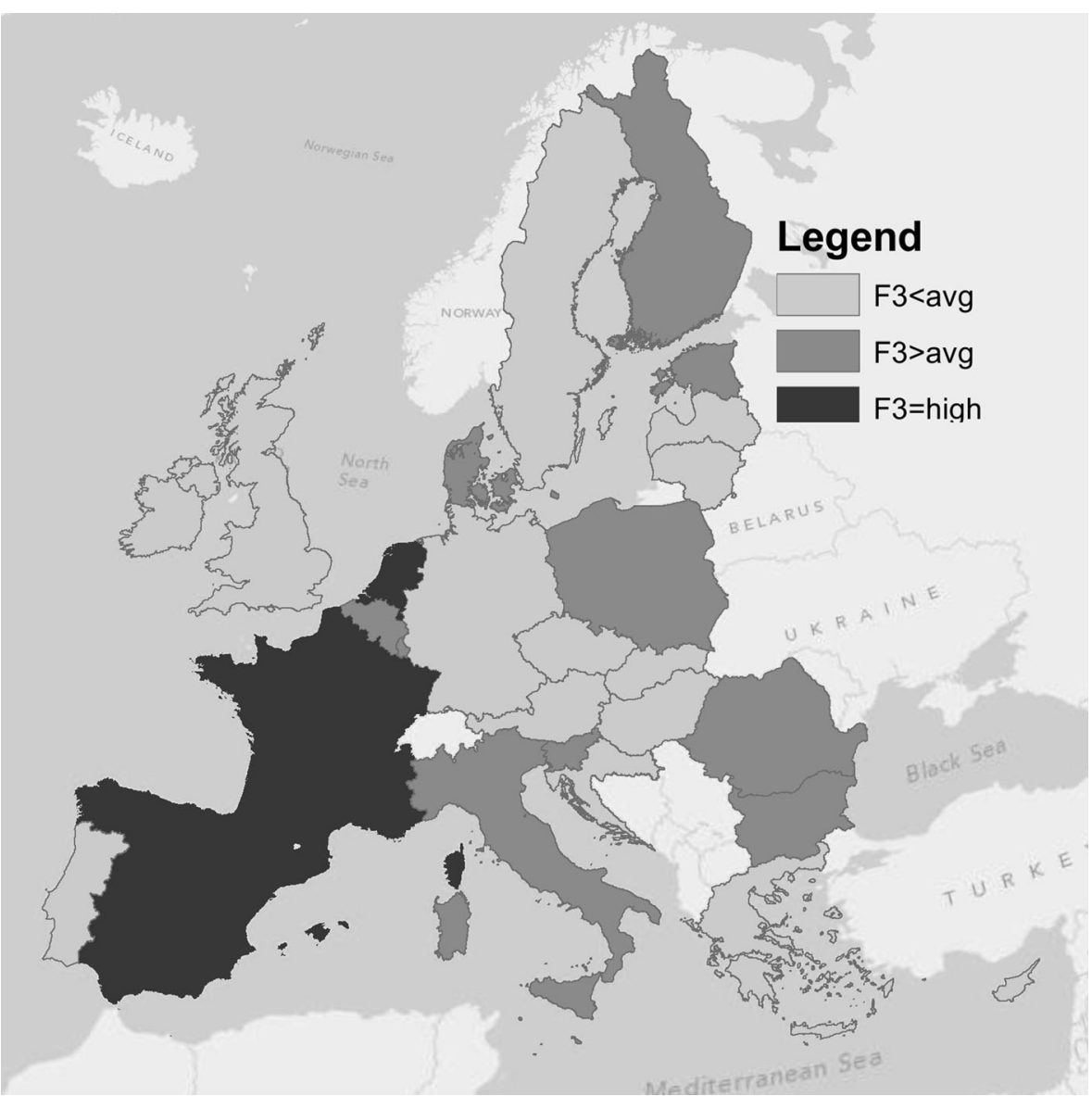

Fig. 6 Factors of the rebound effect in EU countries (2006-2012): national patterns of electric energy consumption impacts (F3)

\section{Concluding Remarks}

The observed coincidence over time of the growth of ICT and electric consumption in EU countries is not a simple relationship of demand for services. Transformation of the initial input observed variables using a shift and share analysis followed by factor analysis revealed the latent components, i.e. factors interpreted as: the international impacts of the ICT sector, the international pattern of electric energy consumption impacts and, finally, country specific patterns of electric energy consumption impacts. Since 2006, EU countries have formed spatial clusters which are characterized by a similarity in the observed latent factors, forming simultaneously compact zones. These compact zones reveal the spatial footprints of rebound effects and their specificity (Fig.7).

A compound measure of all three factors was simultaneously calculated and presented on the map (Fig.7) as the root mean squares (RMS) of the scores of all three factors. The compound map shows that it is not the absolute size of 


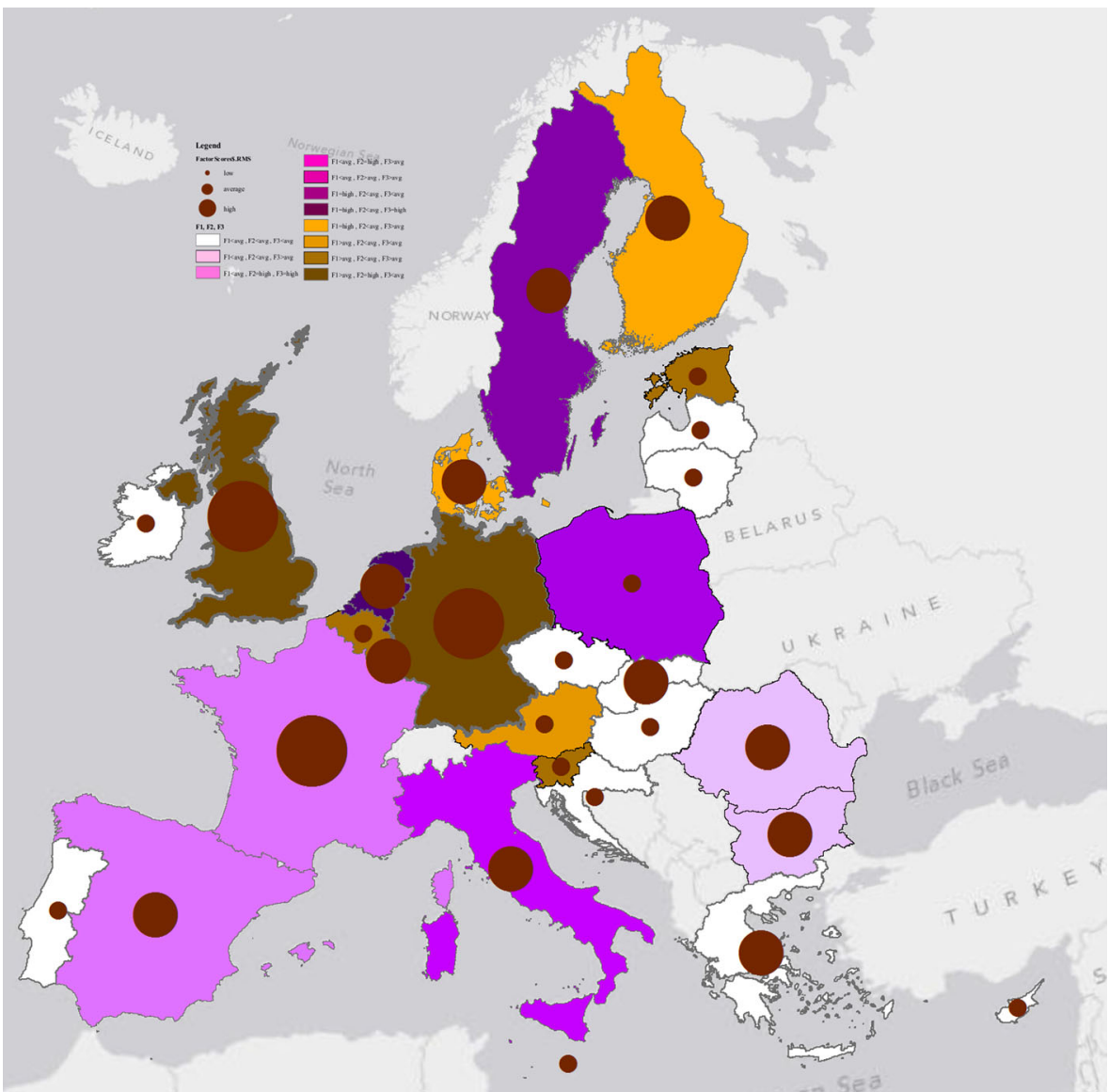

Fig. 7 Average (RMS) of factor scores of international ICT impacts (F1), international pattern of electric energy consumption impacts (F2) and national patterns of electric energy consumption impacts (F3) in EU countries (2006-2012, results of factor analysis, see description in text, base map ESRI, De Lorme; ArcGIS)

the country that matters, but its location. The neighbourhood also matters, as well as peripheral location, near the boundaries of the EU area, which is related to the lower international impacts of ICTs and greater impacts of regional (country) patterns of households' electric energy consumption.

These scientific conclusions may be a tip (or hint) for decision-makers and stakeholders at different levels: i.e. for whole UE, at country level, and even at local administrative units levels (lands, provinces, etc.). There are complex relations among the highlighted above factors. They can be treated as independent targets of energy and information society policies but simultaneously these factors are interdependent phenomena. Rebound effect should be also included in the costs of advantages of ICT development i.e. increase of quality of life, easier social communication, and better, new goods and services which facilitate the daily life and work. Dynamics of ICT dissemination becomes the most important factor of changes in consumer behaviour of people and the whole technical culture of societies. 
Acknowledgments The project, Spatial Differentiation of Information Society Vulnerability to Defined Environmental Hazards in Poland, is supported by Polish National Science Centre (DEC-2011/03/B/HS4/ 04933).

Open Access This article is distributed under the terms of the Creative Commons Attribution License which permits any use, distribution, and reproduction in any medium, provided the original author(s) and the source are credited.

\section{References}

Baliamoune-Lutz, M. (2003). An analysis of the determinants and effects of ICT diffusion in developing countries. Information Technology for Development, 10(3), 151.

Batty, M. (2006). Rank clocks. Nature, 444(7119), 592-96. doi:10.1038/nature05302.

Blair, D. W., \& Mabry, R. H. (1980). An application of the shift-share technique. Growth and Change, 11(1), 48-51. doi:10.1111/j.1468-2257.1980.tb00429.x.

Bomhof, F., van Hoorik, P., \& Donkers, M. (2009). Systematic analysis of rebound effects for 'greening by ICT' initiatives. Communications and Strategies, 1(76), 77-96.

Dunn, E. S. (1960). A statistical and analytical technique for regional analysis. Papers in Regional Science, 6(1), 97-112. doi:10.1111/j.1435-5597.1960.tb01705.x.

Golinski, M. (2011). Measuring the information society-state of the Art of the "grand challenge". International Journal of Digital Information and Wireless Communications (IJDIWC), 1(2), 314-31.

Hilty, L.M. (2008). Information Technology and Sustainability: Essays on the Relationship between Information Technology and Sustainable Development. Norderstedt: Books on Demand.

ITU. (2009). Measuring the information society the ICT development index. Geneva, Switzerland: International Telecommunication Union. Retrieved from http://www.lib.washington.edu/msd/ ip-restricted/b61110668.pdf . Accessed 25 January 2014.

ITU. (2012). Measuring the information society 2012. Geneva: International Telecommunications Union. http://www.itu.int/ITU-D/ict/publications/idi/ . Accessed 25 January 2014.

ITU. (2013). Measuring the information society 2013. Geneva: International Telecommunication Union. http://www.itu.int/en/ITU-D/Statistics/Pages/publications/mis2013.aspx. Accessed 25 Jan 2014.

Levinson, P. (1998). The soft edge a natural history and future of the information revolution. London: Routledge.

Maurseth, P. B., \& Frank, B. (2009). The German information and communication technology (ICT) industry: spatial growth and innovation patterns. Regional Studies, 43(4), 605-624. doi:10.1080/ 00343400701874149.

Mayor, M., \& López, A. J. (2008). Spatial shift-share analysis versus spatial filtering: an application to spanish employment data. Empirical Economics, 34(1), 123-42. doi:10.1007/s00181-007-0167-9.

Missemer, A. (2012). William Stanley Jevons' the coal question (1865), beyond the rebound effect. Ecological Economics, 82, 97-103. doi:10.1016/j.ecolecon.2012.07.010.

Mitchell, W., Myers, J., Juniper, J. (2007). Extending Shift-Share Analysis to Account for Spatial Effects: A Study Using Australian Census Data. In: Proceedings of the ARCRNSISS Methodology. Tools and Techniques and Spatial Theory Paradigm Forums Workshop, University of Newcastle, Australia, 1517 June 2005, 116. RMIT Publishing.

Oguz, S., Knight, J. (2011). Regional Economic Indicators. Economic \& Labour Market, 133, http://www.ons.gov.uk/ons/rel/regional-trends/regional-economic-indicators/November-2010/ regional-economic-indicators-November-2010.pdf (accessed March, 31, 2014).

Woźniak, D., \& Mogiła, Z. (2013). Analysis of Employment Change in the Manufacturing Sector of Voivodeships Economies. Application of the Extended Shift-Share Technique. In: Programming Regional Development In Poland. Theory And Practice. In: Kudłacz, T., Woźniak, D. (eds). Studia Regionalia, 35, Polish Academy of Sciences Committee for Spatial Economy and Regional Planning, Wrocław pp. 163-176. 